\title{
UTR vs. CU Formation: The Missing CET
}

\author{
Ali M. El-Agraa \\ Fukuoka University \\ Anthony J. Jones \\ University of Leeds
}

\begin{abstract}
In 1965, Cooper and Massell (CM), using a partial-equilibrium trade model, reached the conclusion that a policy of unilateral tariff reduction (UTR) is superior to the formation of a customs union (CU). Wonnacott and Wonnacott (WW) challenged this conclusion in 1981 by claiming to show that UTR need not dominate a CU. In this article, we demonstrate that the incorpo ration of a common external tariff in WW? SCU model not only restores the validity of $C M$ ?s conclusion but also leads to the new proposition that the mutual adoption of non-discriminatory free trade policies is superior to UTR.
\end{abstract} (JEL Classifications: F13, F02) 《Key Words: Tariffs, Customs Unions, Unilateral Policies>

* Correspondence Address: Professor of International Economics and European \& American Economies, F aculty of Commerce, Fukuoka University, J apan and Visiting Professor of E conomics 1997-8, Vanderbilt University. (E-mail) ali.m.el-agraa@vanderbilt.edu (until August 1998); elagraa@jsat.fukuoka-u.ac.jp (from September 1998).

Senior Lecturer, School of Business and Economic Studies, the University of Leeds, UK.

@2000 - Center for International E conomics, Sejong Institution. All rights reserved. 


\section{Introduction}

The proposition that at least one member of any potential customs union (CU) could always gain more by a policy of unilateral tariff reduction (UTR) was first demonstrated by Cooper and Massell ([1965a]; $C \& M$ hereafter). Although their argument was set in a partial equilibrium framework, Krauss [1972] subsequently showed that the same result could be obtained in the orthodox two-commodity, three-country general equilibrium model of $\mathrm{CU}$ formation. For a decade and a half, this proposition was accepted as valid in so far as it referred solely to the static resource reallocation effects of international economic integration. However, Wonnacott and Wonnacott ([1981]; W\&W hereafter) then contested this view by arguing that a CU can dominate UTR, but although Berglas [1983] challenged the nature of their analysis, reaching the conclusion that their claim was categorically wrong (p. 1142 - see footnote 2), W\&W interpreted Berglas' response to be supportive of their ?much weaker proposition ... that UTR is sometimes superior, sometimes inferior" to a CU (W\&W [1984]: 491), without Berglas coming back to challenge their representation of his position, since it is the official policy of the American Economic Review not to allow the publication of a further response by a critic of one of its articles.

Our contention is that the $W \& W$ analysis is incomplete, not only because of the rationale provided by B erglas (see footnote 2), which concentrates on missed different assumptions and missing tariffs by the $\mathrm{CU}$ partner $(\mathrm{P})$ and rest of the world (W) but also, and more importantly, because of a fundamental omission in their own analysis. The purpose of this article is to prove our contention, but in the process we also provide an alternative proposition pertinent to the $W \& W$ framework. Needless to add that, in response to those who may ask why this issue is being reopened after having lain dormant for over a decade, the revival is necessitated by its vital importance to the $\mathrm{CU}$ literature, the recent proliferation in economic integration schemes (see El-Agraa [1997a]), and the intensification of the integrative efforts, especially in Europe (see El-Agraa [1997b]). 


\section{W\&W's Claim and Our Contention}

$\mathrm{W} \& \mathrm{~W}$ indeed argue that the 'UTR dominates a CU' proposition does not hold generally if the following assumptions are rejected:

(i) that the tariff imposed by $P$ can be ignored;

(ii) that $\mathrm{W}$ has no tariffs; and

(iii) that there are no transport costs between members of the CU (P and the home country, $\mathrm{H}$ ) and $\mathrm{W}$.

Their approach is not based on terms of trade effects or economies of scale, and, except for their rejection of these three assumptions, their argument is set entirely in the context of the standard two-commodity, threecountry framework of CU theory.

Although we disagree with W\&W's claim that assumptions (i) and (ii) are implicit in the literature of CU theory, we share their view that they should be rejected. Contrary to their claim, however, we shall demonstrate that the rejection of both these assumptions, with or without the rejection of (iii), has no effect on the validity of $C \& M$ ? s conclusion. ${ }^{1}$ This is because $W \& W$ have themselves ignored an assumption which, although normally left unstated, must surely be regarded as fundamental to the analysis of CUs:

\section{the creation of a $\mathrm{CU}$ requires the establishment of a common external tariff (CET) which is effective in reducing or prohibit - ing the external trade of member countries with $W$.}

Given this assumption, we shall prove that the proposition that UTR is superior to the formation of a CU remains logically true within the model

1. Berglas stressed that $W \& W$ had ignored two alternative assumptions implicit in the CU literature: (i) trade before and after the $\mathrm{CU}$ formation could be represented by the same flow diagram, i.e. the direction of trade should be unaffected by the CU; and (ii) all three countries participated in trade. He then demonstrated that W\&W had ignored these assumptions in their analysis, and added that the proposition that "UTR is preferable to CU formation" when the direction of trade does not change ( $p$. 1142 ) was an interesting one. He concluded that W\&W's analysis could be conceived as a demonstration that this proposition may fail to hold when the direction of trade does change, but added that "the damaging statement that the proposition does not hold if transport costs and tariffs in nonunion countries is allowed for is simply incor rect (p. 1142; our italics). 
employed by $W \& W$, even when, as they desire, explicit account is taken of tariffs in $\mathrm{P}$ and $\mathrm{W}$, and of the likelihood of significantly higher transport costs on trade between members of the $\mathrm{CU}$ and $\mathrm{W}$ than on intra-union trade.

The rejection of assumptions (ii) and/ or (iii) above, however, does lead to the further conclusion that UTR is not necessarily the optimal trade policy. It is our contention that, in this case, the basic general conclusion in any two-commodity general equilibrium model in which all domestic distortions from Pareto optimality are directly offset by the appropriate use of (firstbest) domestic policy instruments can be stated as:

\section{for any two countries which are faced both by a fixed trading policy in $\mathbf{W}$ and by constant terms of trade, the optimal action available to both countries is always the mutual adoption of non-discriminatory free trade policies (MFT) combined, where necessary, with appropriate lump-sum transfers of income between the two countries}

We shall also argue that $C \& M$ 's proposition can then be seen as reflecting a special case of our more general conclusion. This occurs when no formal cooperation need be required to achieve MFT which should be reached instead by each country independently acting optimally in its own national interests by adopting UTR. C\&M 's special case, however, is the only one that matters for $\mathrm{CU}$ theory because it coincides exactly with the case where a positive CET affects the volume of the partners? exter nal trade with $W$.

\section{Clarifying the UTR vs. CU Formation Issue}

Although W\&W cite various sources for the proposition that UTR is superior to a $\mathrm{CU}$, they do not distinguish clearly enough between those writers, such as Krauss [1972], who seem to regard the proposition as evidence of the basic irrationality or non-economic nature of the formation of a $\mathrm{CU}$, and those, like C\&M [1965a], who introduced the proposition as evidence of the inadequacy of one particular, highly simplified, framework of CU theory. It is the latter interpretation which we have supported in the past and which we continue to support on the grounds that this basic, 'small country' framework excludes many of the features which may prove more relevant to the 
economic case for the adoption of preferential trading arrangements and that the theoretical analysis should concentrate on seeing whether the conclusions of the basic framework are sensitive to the relaxation of its assumptions (see Jones [1980a] and El-Agraa [1984]).

$C \& M$ 's own stand on this issue is indicated by their immediate attempt (C\&M [1965b]) to develop an alternative framework of analysis and at least three general kinds of 'rational economic' explanation for the formation of a CU can now be offered to contradict the claim that the 'UTR dominates CU' proposition is of general validity.

Perhaps the most important of these was suggested by Arndt [1968] in an early response to $C \& M$ and relies on the possibility, which had received earlier attention in, for example, the work of J ohnson [1960] and M eade [1955], of variable terms of trade with $\mathrm{W}$. The case has now been extensively treated in the literature by, inter alia, Negishi [1969], Kemp [1969], Takayama [1972] and Richardson [1995], and the generality of its main conclusions has been indicated by Kemp and Wan [1976]. As has been argued elsewhere by Jones [1980b], the principal conclusion of such a 'large union' model is that the formation of a $\mathrm{CU}$ is preferable to all other unilateral or joint trade policies of the members provided:

(a) that the CET rate is set equal to the reciprocal of the elasticity of W's export supply curve (i.e. at the optimum tariff rate);

(b) that W's trade policy is fixed; and

(c) that an appropriate intra-CU redistribution policy be arranged so as to ensure that all members share in the joint gains.

Although W\&W acknowledge this argument in the sense that they recognize that the 'UTR dominates CU' proposition is dependent on the 'small country' assumption of fixed international terms of trade, they do not point out explicitly that it is the 'large union' model which represents the general case and that the special case represented by the 'small country' model is of interest more for its identification of the conditions that are necessary for the optimality of unilateral policy of free trade than for any claim to empirical relevance.

$W \& W$ also imply that an equally important limitation of the generality of the 'UTR dominates CU' proposition is provided by the existence of 
economies of scale. This is not true. The existence of decreasing average costs is not a sufficient condition to overturn this proposition (Corden [1972]). In order for economies of scale to provide the basis of an explanation for the formation of a CU, it is also necessary to introduce the assumption that there are 'market imperfections' and 'externalities' which are not being offset by appropriate 'first-best' policies or by other trading policies, such as the use of export subsidies, which appear superior to the formation of a CU (see J ones [1981]: 67-72). As such, however, it forms only one example of the type of explanation of the formation of a CU which was foreshadowed by Johnson [1965]. The general form of this explanation is analogous to the 'second-best' case for the national use of tariffs in the presence of domestic distortions. Given the inability of the partners to offset distortions which are internal to the $\mathrm{CU}$, the optimal use of a second-best instrument, such as the CET, can be justified.

The third argument which further limits the applicability of the alleged superiority of UTR over CU relies on the rejection of the neoclassical framework for the analysis of tariff changes and, instead, adopts a macroeconomic approach in which the output and employment-creating effects of membership of a CU are superior to UTR (see EI-Agraa [1981] and Jones [1982]). However, one cannot rest at ease when the analysis is not based on a general equilibrium framework.

Of course, there may be practical reasons for preferring $\mathrm{CU}$ formation to UTR, especially when tariffs are imposed for revenue-raising purposes, as is the case in many less-developed countries. There may also be theoretical justifications, such as those advanced by Conway et. al [1989]2, but these

2. In their analysis of the relative merits of preferential trading agreements (e.g. CUs) and UTR, Conway et. al [1989] reach the conclusion that CUs are superior for plausible specifications of tastes and endowments. The emphasise, however, that the attractiveness of CUs depends crucially on general-equilibrium effects on intra-union and external terms of trade. Game-theoretic differences between the alternative policy strategies are highlighted: agreements are cooperative equilibria while unilateral action defines a noncooperative Stackelberg equilibrium. The analytical framework is a three-country variant of the D ornbusch-Fischer-Samuelson classical trade model. N umerical simulations also illustrate that agreements may enhance government revenue and "learning-by-doing." 
Figure 1

\section{'UTR dominates a CU'}

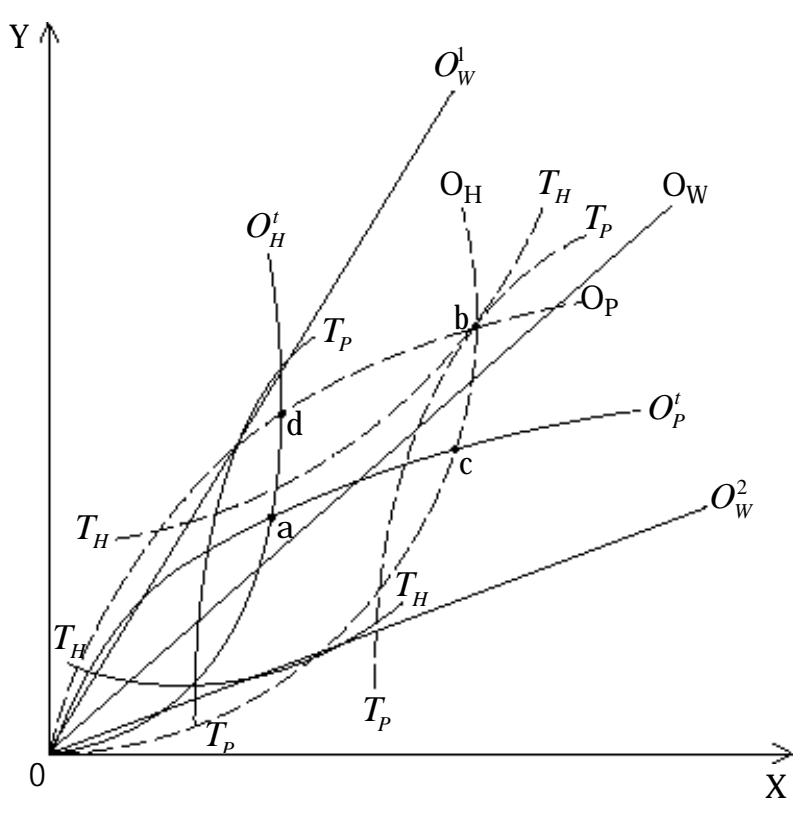

are based on a game-theoretic model with Ricardian characteristics which bears no resemblance to the $W \& W$ model being considered and extended in this paper.

There are therefore ample reasons for agreeing with $W \& W$ that it is appropriate to dispute that "a general case has been made that ' ... a more efficient allocation of resources could not be the reason why [CUs] are formed' (Krauss [1972]: 417)" (Wonnacott and Wonnacott [1981]: 706). Since, however, they have, either explicitly or implicitly, excluded all these arguments from their own rejection of the proposition, the interesting issue raised by their paper is whether or not they have established an alternative reason for limiting the applicability of Krauss's argument.

\section{W\&W's Most Unambiguous Case}

B efore introducing our analysis, a brief exposition of W\&W's most unambiguous case, that of trade creation, is warranted. This is not only because it is essential for clarifying our differences, but also because it forms an essen- 
tial part of our model.

The basic framework of the analysis is set out in Fig. $1 . O_{H}$ and $O_{P}$ are the free trade offer curves of the potential CU partners whilst $O_{H}^{t}$ and $O_{P}^{t}$ are their initial tariff-inclusive offer curves. $O_{W}^{1}$ and $O_{W}^{2}$ are W's offer curves depending on whether the prospective partners wish to import commodity X(i.e. $O_{W}^{1}$ ) or export it $\left(O_{W}^{2}\right)$, with $O_{W}$ being W's free trade offer curve in the absence of both transport costs and tariffs in W. The inclusion of both $O_{H}^{t}$ and $O_{P}^{t}$ meets W\&W's desire to reject assumption (i) whilst the gap between $O_{W}^{1}$ and $O_{W}^{2}$ may be interpreted either as the rejection of (ii) and/ or of (iii) ? see W\&W ([1981]: 708-9). Unlike W\&W, however, in addition to these offer curves, we also include in Fig. 1 various trade indifference curves for $\mathrm{H}\left(T_{H}^{\prime}\right.$ and $\left.T_{H}^{\prime \prime}\right)$ and $\mathrm{P}\left(T_{P}^{\prime}\right.$ and $\left.T_{P}^{\prime \prime}\right)$.

Thus, consider $W \& W$ 's most unambiguous case of trade creation, "where CU benefits are relatively easy to show" (p. 709), and which provides the basis for their ' $\mathrm{CU}$ dominates UTR' proposition. For pure trade creation to occur it is necessary to make the wedges so wide that $\mathrm{H}$ and $\mathrm{P}$ trade within either section of it both before (at point a) and after (at point b) CU formation. This is tantamount to stating that W's existence is of no consequence for $\mathrm{H}$ and $\mathrm{P}$. Hence, with W "out of the picture", the question of whether or not $\mathrm{H}$ and $\mathrm{P}$ should form a $\mathrm{CU}$ becomes one of a two-country free trade situation. W\&W conclude that "in this case a CU can easily be shown to be beneficial under standard assumptions; both countries have higher welfare at [point b] than at [point a]. M oreover, for each countr $\mathrm{y}$, a CU dominates unilateral free trade: $[H]$ has higher welfare at [point b] than at [point $c$ ], while [P] is better off at [point b] than [at point d]" (p. 709; italics added).

$W \& W ' s$ conclusion seems convincing, but before subjecting it to close scrutiny, one needs to ask about the absence of a CET by the CU partners. Contrasting a $\mathrm{CU}$ without one with $\mathrm{C} \& \mathrm{M}$ 's, which has at least a tariff by $\mathrm{H}$, is simply not comparing like with like. Thus, one needs to intoduce such a CET before going further.

\section{The Case of a CU with Trade with $W$}

In order to demonstrate the importance of incorporating the CU'S CET, we shall begin by introducing what may at first sight appear to be an 
Figure 2

A CU with a CET

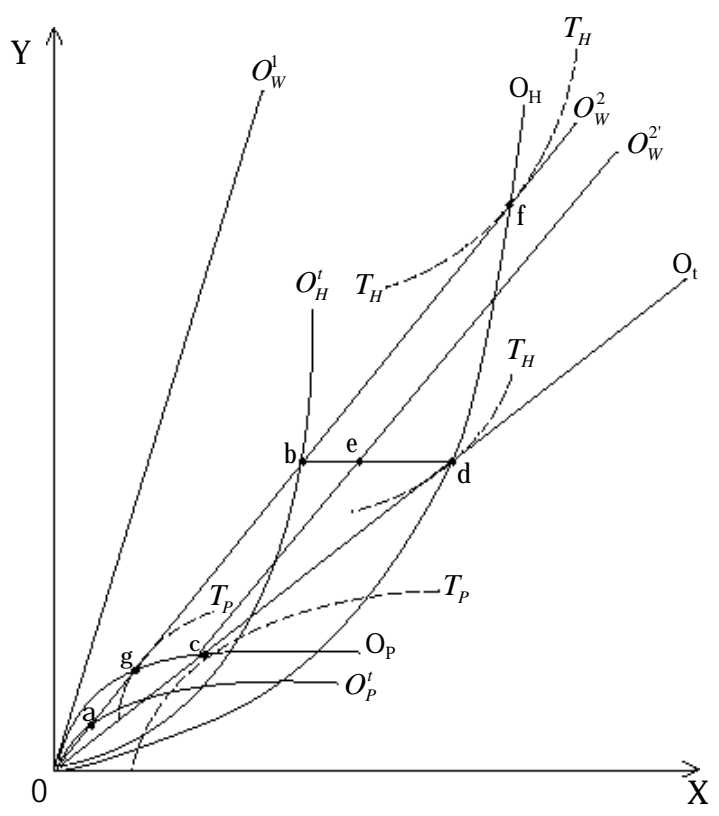

unorthodox model, but it is one which highlights features that are most pertinent to our contention.

Consider Fig. 2, which is a variation on Fig. 1 and which, in addition, includes the pre- $\mathrm{CU}$ domestic terms of trade in $\mathrm{H}\left(\mathrm{O}_{\mathrm{t}}\right)$ as well as new terms of trade $O_{W}^{2}$, drawn parallel to $O_{W}^{2}$ from point c where $\mathrm{O}_{\mathrm{p}}$ intersects $\mathrm{O}_{\mathrm{t}}$ for the reason which is about to follow.

The diagram is drawn to illustrate the case where a $\mathrm{CU}$ is formed between $\mathrm{H}$ and $\mathrm{P}$ with the CET set at the same rate as $\mathrm{H}$ 's initial tariff rate on imports of $X$ and where the domestic terms of trade in $\mathrm{H}$ remain unaltered so that trade with $\mathrm{W}$ continues after the formation of the $\mathrm{CU}$. With its initial non-discriminatory tariff, $\mathrm{H}$ will trade along $\mathrm{O}_{W}^{2}$ with both $\mathrm{P}(\mathrm{Oa})$ and $\mathrm{W}(\mathrm{ab})$. The formation of the $\mathrm{CU}$ means that $\mathrm{H}$ and $\mathrm{P}$ 's trade is determined by where $\mathrm{O}_{\mathrm{p}}$ intersects $\mathrm{O}_{\mathrm{t}}$ (i.e. at c) and that $\mathrm{H}$ will trade with $\mathrm{W}$ along $c \mathrm{O}_{W}^{2^{\prime}}$ (drawn parallel to $O_{W}^{2}$ to meet the above assumption of continued trade with W). The final outcome for $\mathrm{H}$ will depend on the choice of assumptions about what happens to the tariff revenue generated by the remaining external trade. If there is no redistribution of tariff revenue in $\mathrm{H}$, then traders in that 
country will remain at point $d$. The tariff revenue generated by the external trade of the $\mathrm{CU}$ with $\mathrm{W}$ is then shown equal to ed(measured in units of commodity $X$ ) which represents a reduction of be compared with the pre-CU tariff revenue in $\mathrm{H}$. Further, if procedures similar to those of the European Union were adopted, the revenue ed would be used as an 'own resource' to be spent/ distributed for the benefit of both members of the $\mathrm{CU}$, whereas the pre-CU tariff revenue (bd) was kept entirely by country $\mathrm{H}$.

It can be seen that country $\mathrm{P}$ will benefit from the formation of the $\mathrm{CU}$ even if it received none of this revenue ( $c$ as against a), but that $H$ will undoubtedly lose even if it keeps all the post-CU tariff revenue (e as against b). This is the case of pure trade diversion and, in the absence of additional income transfers from $\mathrm{P}, \mathrm{H}$ clearly cannot be expected to join the $\mathrm{CU}$ even if it considers that this is the only alternative initial tariff policy. There is no rationale, however, for so restricting the choice of policy alternatives. UTR is unambiguously superior to the initial tariff policy for both $\mathrm{H}$ (moving from b towards f along $O_{W}^{2}$ and $\mathrm{P}$ (moving from a towards $\mathrm{g}$ along $O_{W}^{2}$ ), and, compared with the non-discriminatory free trade policies available to both countries (which take $H$ to $f$ and $P$ to $g$ ), there is no possible system of income transfers ${ }^{3}$ from $\mathrm{P}$ to $\mathrm{H}$ which can make the formation of a CU Pareto superior to free trade for both countries. It remains true, of course, that $P$ would gain more from membership of a $\mathrm{CU}$ with $\mathrm{H}$ than it could achieve by UTR ( $c$ as against moving from a towards $g$ ) but, provided that $H$ pursues its optimal strategy, which is UTR, countr y $P$ itself can do no better than follow suit so that the optimal outcome for both countries is M FT.

Of course, there is no a priori reason why the $\mathrm{CU}$, if created, should set its CET at the level of H's initial tariff. Indeed, it is instructive to consider the consequences of forming a CU with a lower CET. The implication of this can be seen by considering the effect of rotating $\mathrm{O}_{\mathrm{t}}$ anticlockwise towards $O_{W}^{2}$. In this context, the rotating $\mathrm{O}_{\mathrm{t}}$ will show the post-CU terms of trade in both $\mathrm{H}$ and $\mathrm{P}$. Clearly, the lowering of the CET will improve the domestic terms of trade for $\mathrm{H}$ compared with the original form of the $\mathrm{CU}$, and it will have a trade creating effect as the external trade of the $\mathrm{CU}$ increases more

3. Recall that income transfers shift the offer curves in a direction opposite to that in the case of tariffs; hence $O_{H}$ will move clockwise while $O_{P}$ will move anticlockwise. 
rapidly than the decline in intra-CU trade. Compared with the original $\mathrm{CU}$, country $\mathrm{H}$ would gain and $\mathrm{P}$ would lose. Indeed, the lower is the level of the $\mathrm{CET}$, the more likely is $\mathrm{H}$ to gain from the formation of the $\mathrm{CU}$ compared with the initial non-discriminatory tariff ( $\mathrm{H}$ 's trade indifference curve going through $b$, not drawn, will pass to the south of $f$, allowing the rotating $O_{t}$ to go to points between it and $T_{H}^{\prime}$ ). As long as the CET remained positive, however, $\mathrm{H}$ would be unambiguously worse off from membership of the $\mathrm{CU}$ than from UTR, and, although P would gain from such a CU, compared with any initial tariff policy it may have adopted, it remains true that there is no conceivable set of income transfers associated with the formation of the $\mathrm{CU}$ which would make both $\mathrm{H}$ and $\mathrm{P}$ simultaneously better off than they would be if, after H'S UTR, country P also pursued the optimal unilateral action available - the move to free trade.

It is of course true that if the CET is set at zero, so that the rotated $\mathrm{O}_{\mathrm{t}}$ coincides with $O_{W}^{2}$, then the outcome is identical with that for the unilateral adoption of free trade for both countries. However, one cannot describe such a policy as ?the formation of a CU'; a CU with a zero CET is indistin guishable from a free trade policy by both countries and should surely be described solely in the latter terms.

\section{The CET as a Prohibitive Tariff}

A critical feature of the previous argument is that $O_{H}$ and $O_{P}$ intersect to the right of $\mathrm{O}_{\mathrm{t}}$ so that the formation of the $\mathrm{CU}$ does not completely eliminate the external trade of the CU. Accordingly, consider a second case, as shown in Fig. 3, which employs the same notation as in Fig. 2 with the inclusion of the post-CU domestic terms of trade of the partners, $\mathrm{O}_{U}$. In this case, although the initial position of both countries is essentially the same as in Fig. 2 ( $H$ at b and $P$ at $a$ ), the creation of a CU with a CET equal to $H$ 's initial tariff completely eliminates trade with $\mathrm{W}$ as both $\mathrm{H}$ and $\mathrm{P}$ move to trade at point $\mathrm{c}$ at the post-CU terms of trade $\mathrm{O}_{U}$. M oreover, such a CET is partially (but only partially) redundant as it could be reduced to the level shown by the difference between $O_{W}^{2}$ and $\mathrm{O}_{U}$ without any effects on trade or welfare of the partners who would continue to trade solely with each other. Under such circumstances, which cor respond to the usual case explored in the $\mathrm{CU}$ 


\section{Figure 3}

\section{A CU without trade with $\mathrm{W}$}

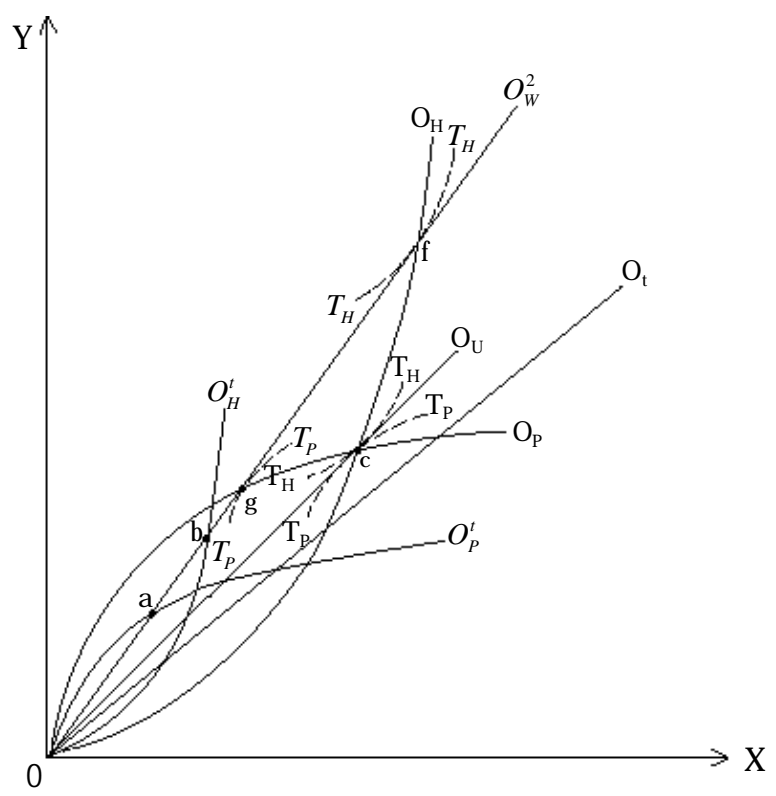

literature, the formation of the $\mathrm{CU}$ causes both trade creating and trade diverting effects and can be superior to the initial tariff policies of both member countries (depending on whether $\mathrm{T}_{H}$ intersects $O_{W}^{2}$ to the southwest or northeast of b along $O_{W}^{2}$ ). Nevertheless, $C \& M$ 's proposition that UTR dominates membership of a $\mathrm{CU}$ is clearly true for $\mathrm{H}$. Further, as in the previous argument, given the unilateral adoption of free trade by $\mathrm{H}$, countr $\mathrm{y}$ $P$ can again do no better itself than move to a free trade policy. It also remains true that $\mathrm{P}$ is unable to offer any income transfers to $\mathrm{H}$ which could leave both countries better off in a $\mathrm{CU}$ than they would be with free trade.

If the CET is lowered below its prohibitive level, then the resulting $\mathrm{CU}$ will retain some trade with $\mathrm{W}$ and it can be seen that the lower is the CET the more favourable will the $\mathrm{CU}$ be to $\mathrm{H}$ (and the less favourable will it be to $P$ ). Provided the CET is positive (i.e. provided a CU is formed), however, the conclusion that MFT dominates the formation of the CU holds.

The conclusion also remains valid if the intersection of $O_{H}$ and $O_{P}$ is moved closer to $O_{W}^{2}$. In the limiting case, where the intersection occurs along $O_{W}^{2}$, the formation of a CU is equivalent to free trade. Since, however, 
in this case any CET is entirely redundant, again, one should not view this as an example of a problem of preferential trading policy when the identical outcome is achievable by UTR.

\section{The Case Where UTR Is Not the Optimal Policy}

A critical feature of both the previous arguments is that UTR is the optimal policy for $\mathrm{H}$ and that when $\mathrm{H}$ adopts this policy, it is also the optimal policy for P. No mutual cooperation, negotiation or preferential treatment is required. It is also notable that the existence of the wedge between $O_{W}^{1}$ and $O_{W}^{2}$ suggested by W\&W has no significant role to play in either of the previous two cases. The essential reason for this is that both Figs. 2 and 3 have been drawn so that the free trade indifference curve of countr y $\mathrm{H}\left(T_{H}^{\prime}\right)$ does not intersect the free trade offer curve of $P\left(O_{p}\right)$.

This possibility is depicted in Fig. 4. The initial trading position, point $\mathrm{m}$ for both $\mathrm{H}$ and $\mathrm{P}$, can be envisaged as resulting from the efforts of $\mathrm{H}$ to establish a unilateral optimum tariff policy without taking into account the retaliatory action of country P. As is well established in the orthodox twocountry model, rounds of retaliatory action by both countries may lead to a tariff-ridden equilibrium in which neither country can gain from further unilateral action. The essential feature of such a tariff-ridden equilibrium is that each country must be trading at a point at which its own trade indifference curve is tangential to the tariff-inclusive offer curve of its trading partner? as shown at point $m$. Unlike the orthodox two-country model, however, the tariff-inclusive equilibrium position must lie within an area which is enclosed both by the free trade offer curves of $\mathrm{H}$ and $\mathrm{P}$ and by the trade indifference curves ( $T_{H}^{\prime}$ and $T_{P}^{\prime}$ ) which can be reached by either country, regardless of the tariff policy of its potential partner, by free trade with $W$.

Given such an outcome (as shown by Fig. 4), however, UTR by either $\mathrm{H}$ or $\mathrm{P}$ cannot achieve any further gains in national welfare. $\mathrm{M}$ embership of a $\mathrm{CU}$ in which the CET effectively prohibited trade with $\mathrm{W}$ would enable both countries to move to point $C$. Although this would benefit $P$, such a policy is worse for $\mathrm{H}$ than would be a policy of UTR so we again see that, for one country, UTR dominates membership of a CU even where, as in this case, both policies are inferior to the initial position. 


\section{Figure 4}

\section{CU Formation from a Tariff-Cum-Retaliation Optimal Position}

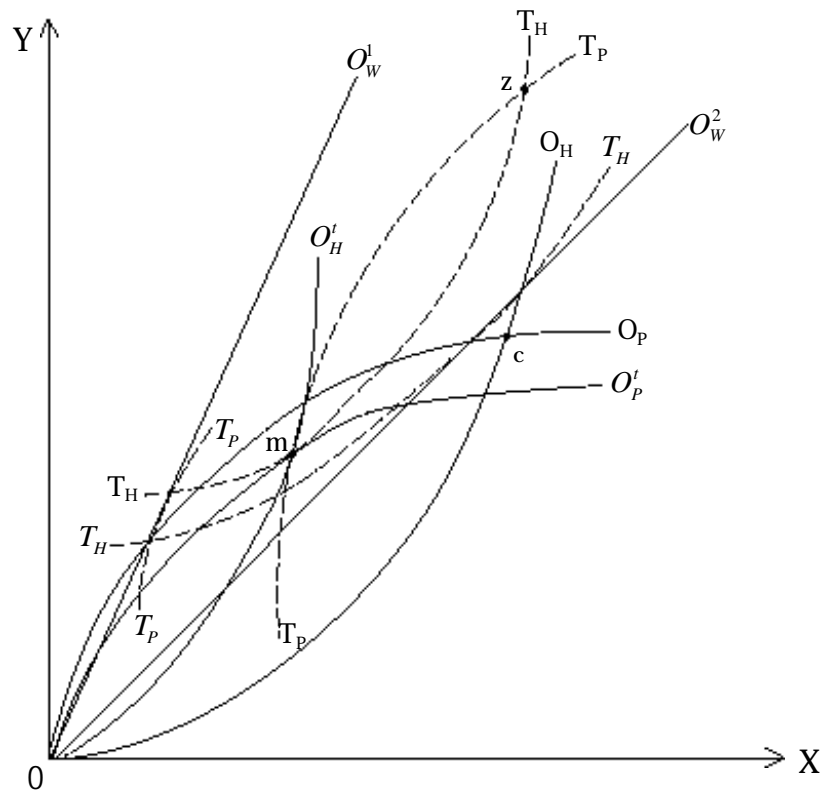

Unlike the earlier cases, however, the potential exists for both countries to gain by cooperating to change their trading policies so that the trading equilibrium lies within the area of mutual advantage bounded by $T_{H}$ and $T_{P}$ between points $M$ and $z .{ }^{4}$ Ideally, of course, the trading equilibrium should move to a point on the contract curve. Such a cooperative bargain would require either the elimination of both countries' tariffs plus a lump-sum transfer from $\mathrm{P}$ to $\mathrm{H}$ or the (non-discriminatory) reduction of country $\mathrm{H}$ 's tariff in return for the introduction by $\mathrm{P}$ of a (non-discriminatory) trade subsidy. ${ }^{5}$ Such cooperation by $\mathrm{H}$ and $\mathrm{P}$, however, does not require the formation of a CU since any movement into the zone of mutual advantage can be achieved without the need for any tariff on trade with $\mathrm{W}$. Indeed, this is true of any outcome which lies within the wedge between $O O_{W}^{1}$ and $O O_{W}^{2}$, hence lack of recognition of this reality will cause a confusion between mutual nondiscriminatory cooperation and the formation of a $\mathrm{CU}$.

4. See El-Agraa [1979a, 1979b, 1981, 1984] for a generalised exposition.

5. For a proof of the formal equivalence of these two policies, see M eade [1952]. 


\section{Figure 5}

\section{Trade Diversion in a CU with a CET}

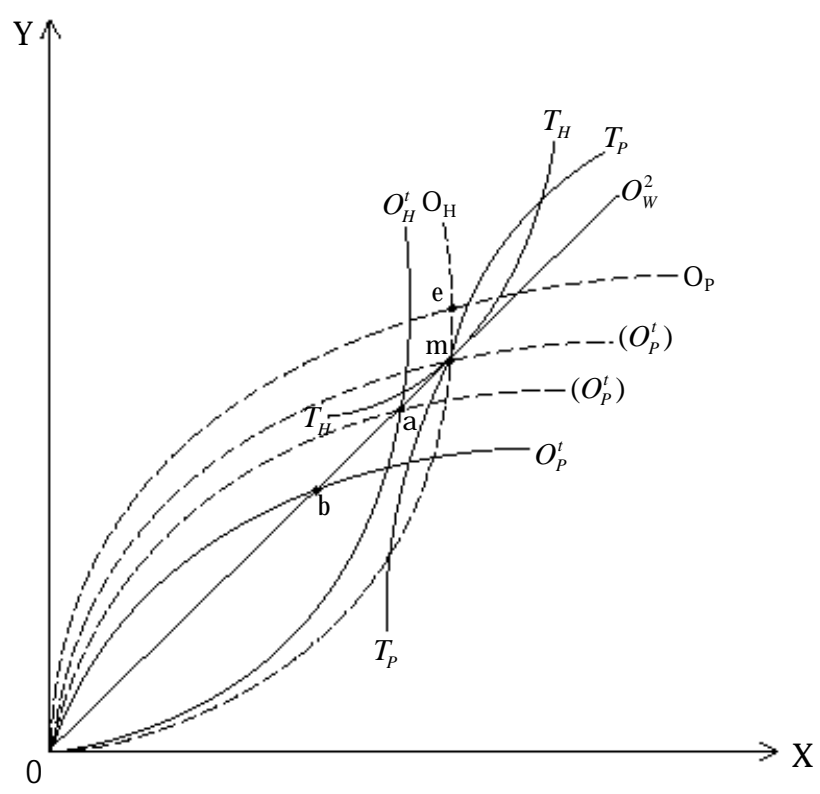

\section{W\&W's Analysis of Trade Diversion}

Thus consider the $W \& W$ argument which they employ to illustrate the possibility of gains from trade diversion. Fig. 5 reproduces Fig. 3 in their paper with the addition of the trade indifference curves $T_{H}^{\prime}$ and $T_{P}^{\prime}$. The diagram depicts an initial trading position in which the unilateral tariff policies of $\mathrm{H}$ and $\mathrm{P}$, which result in the tariff-inclusive offer curves $O_{H}^{t}$ and $O_{P}^{t}$ are such that $\mathrm{H}$ trades along $O_{W}^{2}$ both with country $\mathrm{P}(\mathrm{Ob})$ and $\mathrm{W}$ (ba). It can be noted that this position is inevitably sub-optimal for both $\mathrm{H}$ and $\mathrm{P}$. Countr $\mathrm{y} \mathrm{H}$ can gain by the unilateral adoption of a free trade policy so that it moves onto its free trade offer curve $\mathrm{O}_{H}$ and, hence, to a new trading equilibrium at $m$. Equally, country $P$ can gain by unilateral reduction of its own tariff such that its tariff-inclusive offer curve becomes $\left(O_{P}^{t}\right)$ whilst $\mathrm{H}$ retains its initial (sub-optimal) tariff or $\left(O_{P}^{t}\right) *$ if countr y $\mathrm{H}$ adopts free trade. Thus UTR would take both countries to the trading equilibrium at $m$ and, in doing so, would eliminate trade between country $\mathrm{H}$ and $\mathrm{W}$. The unambigu- 
ous gains so achieved, however, although clearly being associated with the replacement of imports from $W$, should not be confused with the trade diversion effect of the formation of a CU. Instead, as the previous argument demonstrates, the gains come from the unilateral correction by both countries $\mathrm{H}$ and $\mathrm{P}$ of policies which were clearly sub-optimal even from the standpoint of purely unilateral action.

Although unilateral trading policies can do no better than achieve the non-Paretian outcome $m$, it again follows that mutual cooperation and bargaining can improve the welfare of both countries by a combination of the removal of P's existing tariff and an income transfer from $H$ to $P$. Again it would be expected that the optimal outcome would lie on the contract curve between $T_{H}^{\prime}$ and $T_{P}^{\prime}$; and $\mathrm{W} \& \mathrm{~W}$ 's outcome shown by point e, although on the contract curve, can be explained only in terms of the existence of relatively impressive bargaining skills in country $\mathrm{H}$. Whether the Pareto-optimal outcome is e, or whether it lies between $T_{H}^{\prime}$ and $T_{P}^{\prime}$, however, the advantages obtained by mutual cooperation do not imply the formation of a $\mathrm{CU}$. The outcome is again simply one of mutual free trade between $\mathrm{H}$ and $\mathrm{P}$ at terms of trade which require neither country to impose any barrier on trade with $\mathrm{W}$, and therefore requires no agreement to form either a $\mathrm{CU}$ or any other form of preferential trading agreement.

\section{W\&W's Analysis of Trade Creation}

We are now in a position to return to $W \& W$ 's most unambiguous case. Recall that Fig. 1 depicted their case of trade creation, but as we have demonstrated, it lacked a CET; hence Fig. 6 adapts Fig. 1 for our purposes. In the case illustrated by Fig. $6, W \& W$ 's conclusion that a ' $C U$ dominates UTR' may seem to be unambiguously correct, but it is not since again point $B$ is attained most simply by M FT; any CET is redundant, hence no discriminatory policy is required. It is also worth noting that point a could lie in any of five possible zones within the wedge between $O_{W}^{1}$ and $O_{W}^{2}$ :

6. Note that the diagram has been drawn so that $T_{H}^{\prime}$ does not go through this area, but, more generally, this area could also be bounded by $T_{H}^{\prime}$. 


\section{Figure 6}

\section{Trade Creation in a CU with a CET}

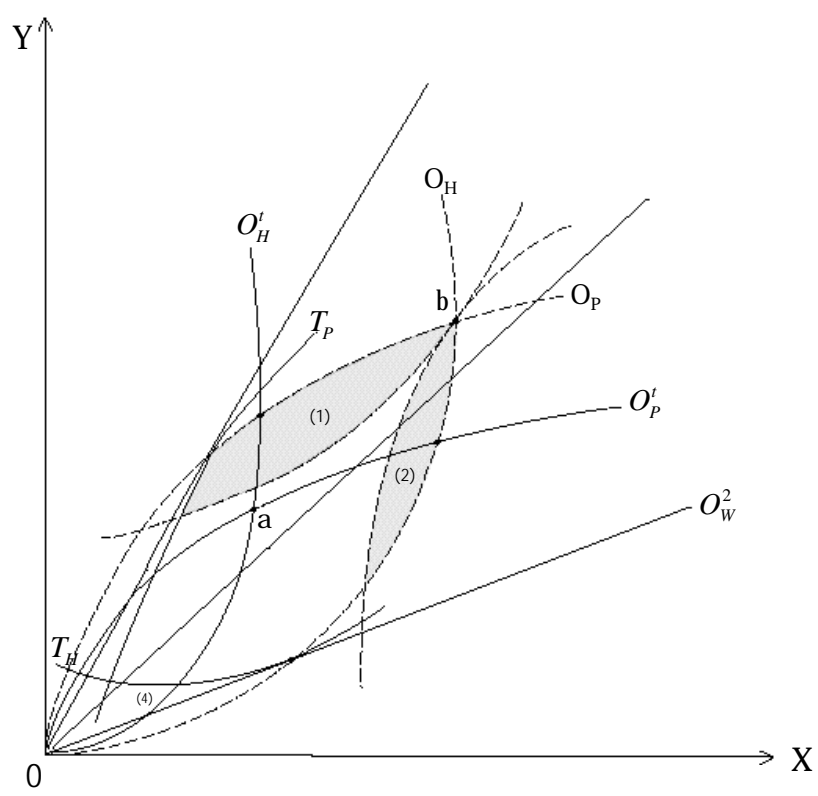

(1) the area bounded by $T_{P}^{\prime}, O_{P}$ and $T_{H}$;

(2) the area bounded by $O_{H}$ and $T_{P} ;{ }^{6}$

(3) the area bounded by $O_{W}^{1}$ and $T_{P}^{\prime}$;

(4) the area bounded by $O_{W}^{2}$ and $T_{H}^{\prime}$; and

(5) the area bounded by $T_{P}^{\prime}, T_{H}, T_{P}, O_{H}$ and $T_{H}^{\prime}$.

In the case illustrated, where point a lies inside zone (5), M FT is itself sufficient to guarantee both countries $\mathrm{H}$ and $\mathrm{P}$ higher welfare levels, i.e. M FT will result in a Pareto superior outcome. Were point a to lie inside either zone (1) or (2), however, simple M FT will result in one country becoming worse off and the other better off in comparison with the initial tariff-ridden situation. In such cases a Pareto superior outcome will require, as in the case considered in fig. 4, both M FT and an appropriate income transfer by one of the two countries. If point a were to lie inside either zone (3) or (4) no formal cooperation would be required to induce either of the two countries to adopt UTR. Thereafter, as illustrated by the possible gains of moving from the non-Paretian outcome (point $m$ in Fig. 5), mutual cooperation can 
improve the welfare of both countries. In all cases, however, given that $\mathrm{O}_{\mathrm{H}}$ and $O_{\mathrm{p}}$ intersect with in the wedge $O_{W}^{1} O_{W}^{2}$, there is no point in cooperation taking the form of the creation of a CU. M oreover, as the earlier arguments illustrate, if $\mathrm{O}_{H}$ and $\mathrm{O}_{\mathrm{P}}$ intersect within the wedge $O_{W}^{1} O_{W}^{2}$, the formation of a CU is inevitably dominated by UTR for at least one of the potential partners.

\section{Many Outside Countries and Commodities}

$W \& W$ 's formal analysis is limited like ours to the two-commodity threecountry framework, but they offer some impressionistic conclusions concerning the extension of their argument to a many-country many-commodity world. We entirely agree with their view that the recognition of this makes it more likely that: (a) the terms of trade faced by the partners are not likely to be constant for all the traded goods; and (b) the trade policy of all outside countries will not be passive in response to changing tariff policies in $\mathrm{H}$ and $\mathrm{P}$. Such views, however, obscure the point that the assumptions of constant terms of trade and a fixed trading policy in $W$ serve the purpose of focusing the analysis solely on the static efficiency aspects of economic integration rather than providing an appropriate general framework for the analysis of all possible economic effects of the creation of a CU. The possibility of using the combined economic power of the $\mathrm{CU}$ members has long been recognised as a rational basis for the formation of a $\mathrm{CU}$, as has the possibility of constraints on the use of first-best domestic policies ? see J ones [1980] and El-Agraa and J ones ([1981], chapter 4). Indeed, M assell [1968] himself welcomed the attempt by Arndt [1968] to analyse the creation of a $\mathrm{CU}$ as a consequence of the terms of trade effects, and $C \& M$ [1965b] provided their own alternative framework for CU analysis in the context of the public good aspects of industrial production in less developed countries.

We see no reason however why the extension of the model to many countries and/ or many commodities should have any effect on the validity of the conclusion that the static resource reallocation effects do not provide a rationale for the formation of a $\mathrm{CU}$. If potential partner countries have no influence on the prices at which they trade with all other countries, then the 
optimal policy available to them, whether acting jointly or alone, is to eliminate all barriers to trade with all countries.

\section{Conclusion}

Cooper and Massell's [1965a] pioneering contribution to the theory of customs unions showed, albeit in a limited and ?orthodox? partial equilibrium framework, that the static efficiency effects of economic integration, to which a disproportionate amount of theoretical attention has been given, do not provide a rationale for the formation of a customs union. Wonnacott and Wonnacott's [1981] challenge to this, although highlighting the importance of taking into account the tariff policies in both partners and in the rest of the world in the orthodox general equilibrium model, has been shown to be inadequate due to their not incorporating a common external tariff for their customs union. In the limited context implied by the assumption of fixed terms of trade with the rest of the world, unilateral tariff reduction dominates the formation of a customs union whenever the formation of the customs union fails to eliminate external trade with the rest of the world or a positive common external tariff is required to prohibit trade with the rest of the world. In some cases, of limited interest, unilateral tariff reduction may not dominate the initial tariff position, but, under such circumstances, the mutual adoption of non-discriminatory free trade policies combined, where necessary, with lump-sum transfers will be optimal and the common external tariff for the customs union will be redundant.

\section{References}

Arndt, S. W. [1968], “On Discriminatory versus N on-preferential Tariff Policies," E conomic Journal 78; pp. 971-9.

Berglas, E. [1983], "The Case for U nilateral Tariff Reductions: Foreign Tariffs Rediscovered," American E conomic Review 73; pp. 1141-2.

Conway, P., D. A ppleyard, and A. Field [1984], "Trade Agreements vs. Unilateral Tariff Reductions: Evidence from M odeling with a Continuum of Goods," International E conomic Review, Vol. 30; pp. 775-94.

Cooper, C. A. and B. F. M assell [1965a], "A New Look at Customs Union 
Theory," Journal of Political Economy 75; 742-7.

Cooper, C. A. and B. F. M assell [1965b], "Towards a General Theory of Cus-

toms Unions in Developing Countries," Journal of Political Economy; 461-76.

Corden, W. M. [1972], "Economies of Scale and Customs Union Theory," Journal of Political E conomy 80; pp. 465-75.

El-Agraa, A. M . [1979a], "On Optimum Tariffs, Retaliation and International Cooperation," Bulletin of E conomic Research 31; pp. 46-53.

El-Agraa, A. M . [1979b], "On Tariff Bargaining," Bulletin of E conomic Research 31; pp. 100-3.

El-Agraa, A. M. [1981], "Tariff bargaining - a correction," Bulletin of Eco nomic Research, Vol. 33; pp. 102-3.

El-Agraa, A. M . [1982], International Economic Integration, (M acmillan, London; St. M artin's Press, New York).

El-Agraa, A. M. [1984], Trade Theory and Policy: Some Topical Issues, (M acmillan, London; St. M artin's Press; New York).

El-Agraa, A. M. [1997a], Economic Integration Worldwide, (M acmillan, London; St. M artin's Press; N ew York).

El-Agraa, A. M . [1997b], The European Union: History, Institutions, E conom ics and Policies, (Harvester Wheatsheaf/ Prentice Hall: Hemel Hempstead).

El-Agraa, A. M . and A. J. Jones [1981], Theory of Customs Unions, (Oxford:

Phillip Allan, St. M artin's Press: New York).

Johnson, H. G. [1953/4], Optimum Tariffs and Retaliation, Review of Eco nomic Studies 21; pp. 142-53.

Johnson, H. G. [1960], "The Cost of Protection and the Scientific Tariff," Journal of Political Economicy 68; pp. 327-45.

Johnson, H. G. [1965], "An Economic Theory of Protectionism, Tariff Bargaining and the Formation of Customs Unions," Journal of Political Economicy 73; pp. 46-58.

Jones, A. J. [1980a], "Domestic Distortions and Customs U nion Theory," Bulletin of E conomic Research 32; pp. 46-58.

Jones, A. J. [1980b], "The Theory of Economic Integration, in A. M. EIAgraa, ed.," The Economics of the European Community, (Philip Allan, Oxford; St. M artin's Press, New York). 
Jones, A. J . [1981], "Orthodox Customs U nion Theory: (1) Domestic Distortions and Scale Economies, in A. M. El-Agraa and A. J. Jones," Theory of customs unions, (Philip Allan, Oxford; St. M artin's Press, New York). Jones, A. J. [1983], "A M acroeconomic Framework for Customs Union theory," Leeds Discussion Papers, 1982, N 0.112. Revised and updated in A. M. El-Agraa, ed., Britain Within the European Community: The Way Forward, (M acmillan, London; Crane Russak, N ew York).

Kemp, M. C. [1969], A Contribution to the General Theory of Preferential Trading, (North Holland, Amsterdam).

Kemp, M. C. and H. Y. Wan [1976], "An Elementary Proposition Concerning the Formation of Customs Unions," Journal of International Eco nomic 6; pp. 95-7.

Krauss, M . B. [1972], "Recent Developments in Customs Union Theory: An Interpretative Survey," Journal of E conomic Literature 10; pp. 413-36.

M assell, B . F . [1968], "A Reply and Further Thoughts on Customs Unions," E conomic Journal 78; pp. 75-8.

M eade, J. E. [ 1955], The Theory of Customs Unions, (N orth Holland, Amsterdam).

Negishi, T. [1969], "Customs Unions and the Theory of Second Best," International Economic Review 10; pp. 391-8.

Richardson, M. [ 1995], "On the Interpretation of the Kemp-Wan Theorem," Oxford E conomic Papers 47; pp. 696-763.

Takayama, A. [1972], International Trade, (Holt Saunders, Eastbourne).

Wonnacott, P. and R. Wonnacott [1981], "Is Unilateral Tariff Reduction Preferable to a Customs Union? The Curious Case of the M issing foreign Tariffs," American Economic Review 71; pp. 704-14.

Wonnacott, P. and R. Wonnacott [1984], "H ow General is the Case for Unilateral Tariff Reduction?," American Economic Review 3; pp. 491. 